M. Habib Ullah*, M. Tariqul Islam, M. Rezwanul Ahsan, Wan Nor Liza Mahadi, Tarik Abdul Latef and M. Jasim Uddin

\title{
A low-cost fiberglass polymer resin dielectric material-based microstrip patch antenna for multiband applications
}

\begin{abstract}
The design analysis and prototype of a compact $8 \times 10-\mathrm{mm}^{2}$ planar microstrip line-fed patch antenna on a readily available, low-cost, reinforced-fiberglass polymer resin composite material substrate is presented in this article. The proposed compact-size antenna has been configured and numerically analyzed using the finite element method-based three-dimensional full-wave electromagnetic field simulator. The optimized design of the antenna has been fabricated on a printed circuit board (PCB), and experimental results have been collected for further analysis. The measurement results affirm the fractional impedance bandwidths of (return loss of less than $-10 \mathrm{~dB}$ ) of 38.78\% (2.03-2.98 GHZ) and 16.3\% (5.38-6.35 GHz), with average gains of 2.52 and $3.94 \mathrm{dBi}$ at both lower and upper bands, respectively. The proposed dual resonant antenna shows the radiation efficiencies of $91.3 \%$ at $2.45 \mathrm{GHz}$ and $87.7 \%$ at $5.95 \mathrm{GHz}$. The stable and almost symmetric radiation patterns and performance criteria of the antenna can successfully cover IEEE $802.11 \mathrm{~b} / \mathrm{g} / \mathrm{n}$, Bluetooth, WLAN, and $\mathrm{C}$-band telecommunication satellite uplinks.
\end{abstract}

Keywords: anechoic measurement chamber; Bluetooth; dual resonant; microstrip antenna; reinforced fiberglass polymer resin; WLAN.

DOI 10.1515/secm-2014-0333

Received September 25, 2014; accepted October 12, 2014; previously published online January 20, 2015

*Corresponding author: M. Habib Ullah, Faculty of Engineering, Department of Electrical Engineering, University of Malaya, Jalan Universiti, 50603 Kuala Lumpur, Malaysia,

e-mail:mhullah@yahoo.com

M. Tariqul Islam and M. Rezwanul Ahsan: Faculty of Engineering and Built Environment, Department of Electrical, Electronic and Systems Engineering, Universiti Kebangsaan Malaysia, 43600 Bangi, Selangor Darul Ehsan, Malaysia

Wan Nor Liza Mahadi and Tarik Abdul Latef: Faculty of Engineering, Department of Electrical Engineering, University of Malaya, Jalan Universiti, 50603 Kuala Lumpur, Malaysia

M. Jasim Uddin: Faculty of Science and Engineering, Networks Communications Engineering, Queensland University of Technology, 2 George Street, Brisbane, QLD 4000, Australia

\section{Introduction}

Planar microstrip patch antennas have recently come to the attention of researchers in multidimensional fields, especially in antenna technology. Owing to the everincreasing demand of higher data speeds, compact broadband and multiband antennas have played a significant role in the fast pace of wireless communication development. The inherited properties of patch antennas such as low cost, light weight, low profile, simple geometric structure, and painless integration to the systems make them suitable for developing compact, efficient wireless mobile component [1]. To fulfill the recent user demand for compact multipurpose wireless devices, it is essential to integrate miniature antennas that are compatible with more than one application. There are requirements for microstrip patch antennas that operate at more than one frequency, such as simple and compact structure, wide bandwidth, low cost, low profile, stable radiation pattern, and consistent gain $[2,3]$. Nonetheless, the antenna design complexity increases with the number of operating frequency bands. Many researchers have concentrated their research on designing microstrip patch antennas that can cater services for multiple applications. For that purpose, several different techniques have been employed by the researchers, such as implementing a slot configuration on the radiating patch $[4,5]$ or using a metamaterial branchline coupler [6], a multilayer patch [7, 8], a shorted patch $[9,10]$, parasitic element $[11,12]$, or fractal shape radiating patch [13]. Recently, a fiberglass polymer resin composite material-based patch antenna was designed and implemented for dual band applications [14] and an experimental study of epoxy resin as a radome for patch antennas was conducted [15].

The well-known frequency band for the Bluetooth and WLAN applications, from 2.4 to $2.484 \mathrm{GHz}$, and for C-band telecommunication satellites, from 5.925 to $6.425 \mathrm{GHz}$, can be covered by a single antenna [16, 17]. A considerable number of antenna researchers have conducted comprehensive studies on antenna design for 
multiple band applications. A $90 \times 50-\mathrm{mm}^{2}$ triple-band antenna for WLAN applications was proposed at $2.4 \mathrm{GHz}$ (2.4-2.484 GHz), $5.2 \mathrm{GHz}(5.15-5.35 \mathrm{GHz})$, and $5.8 \mathrm{GHz}$ $(5.725-5.825 \mathrm{GHz})[18]$. With an overall size of $40 \times 30 \mathrm{~mm}^{2}$, triangular split ring-type antenna has been proposed for the 3.5-GHz WLAN/WiMAX band [19]. A printed S-shaped tri-band antenna with dimensions of $28 \times 15 \mathrm{~mm}^{2}$ was proposed for IEEE $802.1 \mathrm{lb} / \mathrm{g}(2.4-2.484 \mathrm{GHz})$, IEEE 802.11a (5.15-5.35 GHz, $5.725-5.825 \mathrm{GHz}$ ), and HIPERLAN/2 (5.15$5.35 \mathrm{GHz}, 5.47-5.725 \mathrm{GHz}$ ) operations [20]. A printed circuit board (PCB) antenna with dimensions of $30 \times 30 \mathrm{~mm}^{2}$ was proposed for UWB operation [21]. However, there are still some scopes to enhance the performance of the antennas in terms of bandwidth, efficiency, radiation pattern, and gain compared with existing reported antennas.

In this article, a low-profile, compact, S-shaped slotted microstrip patch antenna has been proposed. The antenna has been designed and printed on less expensive, longlasting 1.6-mm-thick reinforced polymer resin composite material substrate. The measured bandwidth (return loss less than $-10 \mathrm{~dB}$ ) of the proposed antenna is $0.95 \mathrm{GHz}$ (38.78\%) for the lower band from 2.03 to $2.98 \mathrm{GHz}$ and 0.97 $\mathrm{GHz}(16.3 \%)$ for the upper band from $\mathrm{GHz}$ to $6.35 \mathrm{GHz}$. The experimental results from the fabricated antenna prototype show the average gain of 2.52 and $3.94 \mathrm{dBi}$ for the lower band (2.03-2.98 GHz) and upper band (5.38-6.35 GHz), respectively. The almost stable and symmetric radiation pattern makes the proposed antenna suitable for IEEE $802.11 \mathrm{~b} / \mathrm{g} / \mathrm{n}$ applications such as Bluetooth and WLAN and for C-band telecommunication satellite uplinks.

\section{Antenna geometry}

The design procedure of the proposed antenna starts from the radiating patch configuration. The proposed $\mathrm{S}$ shape has been obtained by cutting slots from the rectangular patch. The design schematic and photograph of fabricated of the proposed antenna are shown in Figure 1. The detailed specifications noted on the schematic of the proposed antenna are tabulated in Table 1.

The design and numerical analysis of the modified S-shaped slotted microstrip antenna has been done using three-dimensional (3D) high-frequency electromagnetic structural simulator, HFSS [22]. The proposed antenna is designed and fabricated on a 1.6-mm-thick, market-available, low-cost, durable, reinforced epoxy polymer resin composite material substrate with a dielectric constant $\left(\varepsilon_{\mathrm{r}}\right)$ of 4.6 and a loss tangent of 0.02 using an in-lab LPKF PCB prototyping machine. A woven glass-reinforced epoxy matrix

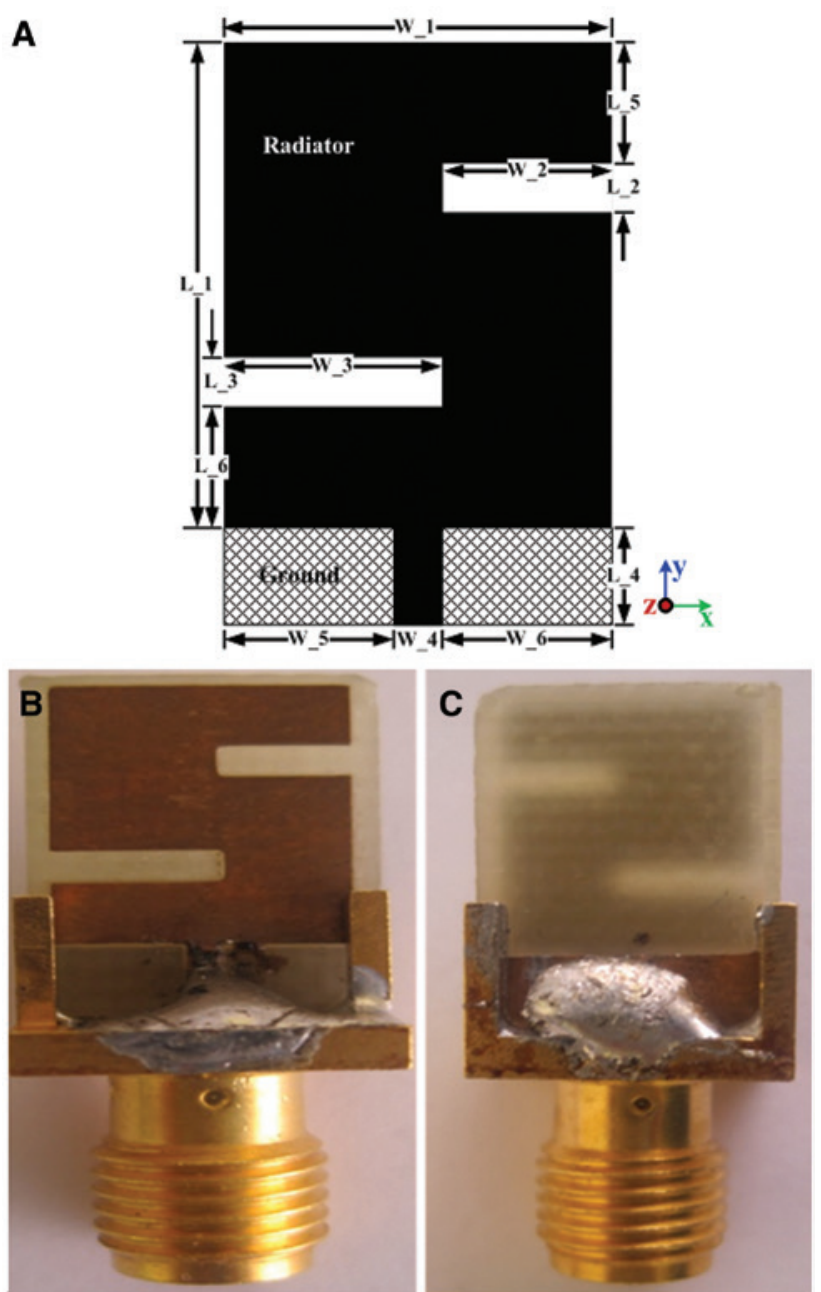

Figure 1 (A) Geometrical configuration, prototype of the proposed antenna. (B) Radiating patch. (C) Ground plane.

Table 1 Optimized parameters of the proposed dual-band antenna.

\begin{tabular}{lrlr}
\hline Parameter & $\begin{array}{r}\text { Dimension } \\
(\mathbf{m m})\end{array}$ & Parameter & $\begin{array}{r}\text { Dimension } \\
(\mathbf{m m})\end{array}$ \\
\hline W_1 & 8 & L_1 & 10 \\
W_2 & 4.5 & L_2 & 1 \\
W_3 & 3.5 & L_3 & 1 \\
W_4 & 1 & L_4 & 2 \\
W_5 & 3.5 & L_5 & 2.5 \\
W_6 & 3.5 & L_6 & 2.5 \\
\hline
\end{tabular}

is used as the substrate material laminated by copper foil on both sides. The strength and durability of the substrate increased due to fiberglass reinforcement. The composition ratio of the material is 60\% fiberglass and 40\% epoxy resin. This composition of epoxy resin and fiberglass varies in thickness and is direction dependent. One of the lucrative advantages of polymer resin composites is that they 
can be shaped and reshaped repeatedly without losing the dielectric properties of the material. The overall design reliability can be considerably improved due to the almost same thermal coefficient of the expansion as the common PCBs used in electronics devices. This intrinsic similarity of thermal expansion characteristics between the PCB with the proposed substrate material, daughterboard, motherboards, and stacked-board electronic integrated modules can significantly decrease temperature-induced solder joint factors during subsequent thermal processing or operation of the final product. Due to the easy fabrication ability, design flexibility, low manufacturing cost, and market availability of the proposed material, it has become prevalent for use as a substrate in patch antenna design. The inner conductor of SMA connector is soldered to the microstrip feed line and the outer conducting part of the SMA is connected to the ground plane.

During the initial design process, the overall dimensions of the radiating patch element intended for the particular operating frequency band must be approximated. For a conventional rectangular microstrip patch antenna, the patch width (W) and length (L) over a ground plane can be calculated using the well-established mathematical

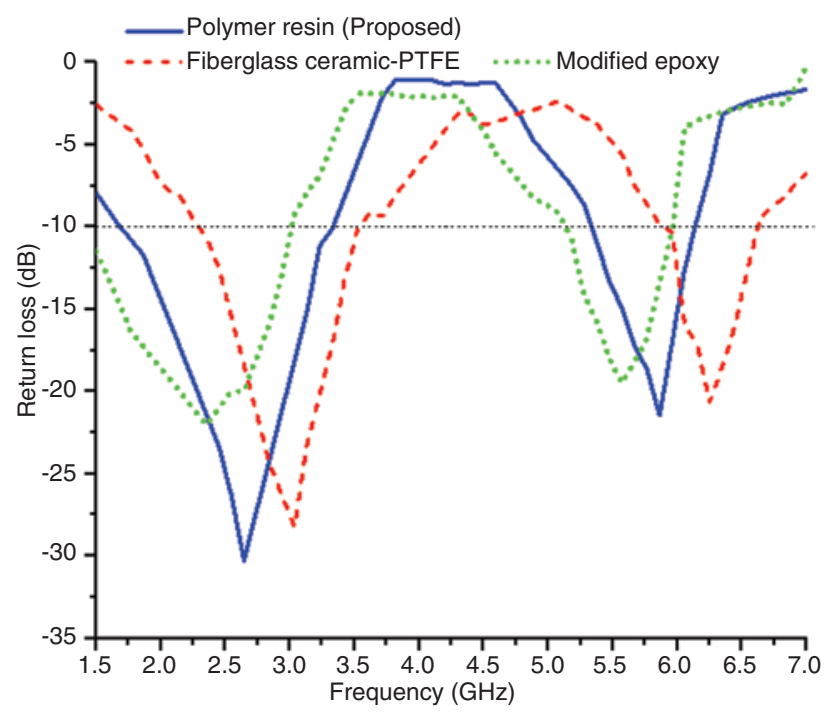

Figure 2 Simulated return loss for three different substrate materials.

Table 2 Dielectric properties of the different substrate materials.

\begin{tabular}{lrr}
\hline Substrate material & $\begin{array}{r}\text { Dielectric } \\
\text { constant }\left(\boldsymbol{\varepsilon}_{\mathrm{r}}\right)\end{array}$ & $\begin{array}{r}\text { Dielectric loss } \\
\text { tangent }\end{array}$ \\
\hline Epoxy resin-fiberglass & 4.6 & 0.02 \\
Ceramic-PTFE & 10.2 & 0.002 \\
Modified epoxy & 4.2 & 0.02 \\
\hline
\end{tabular}
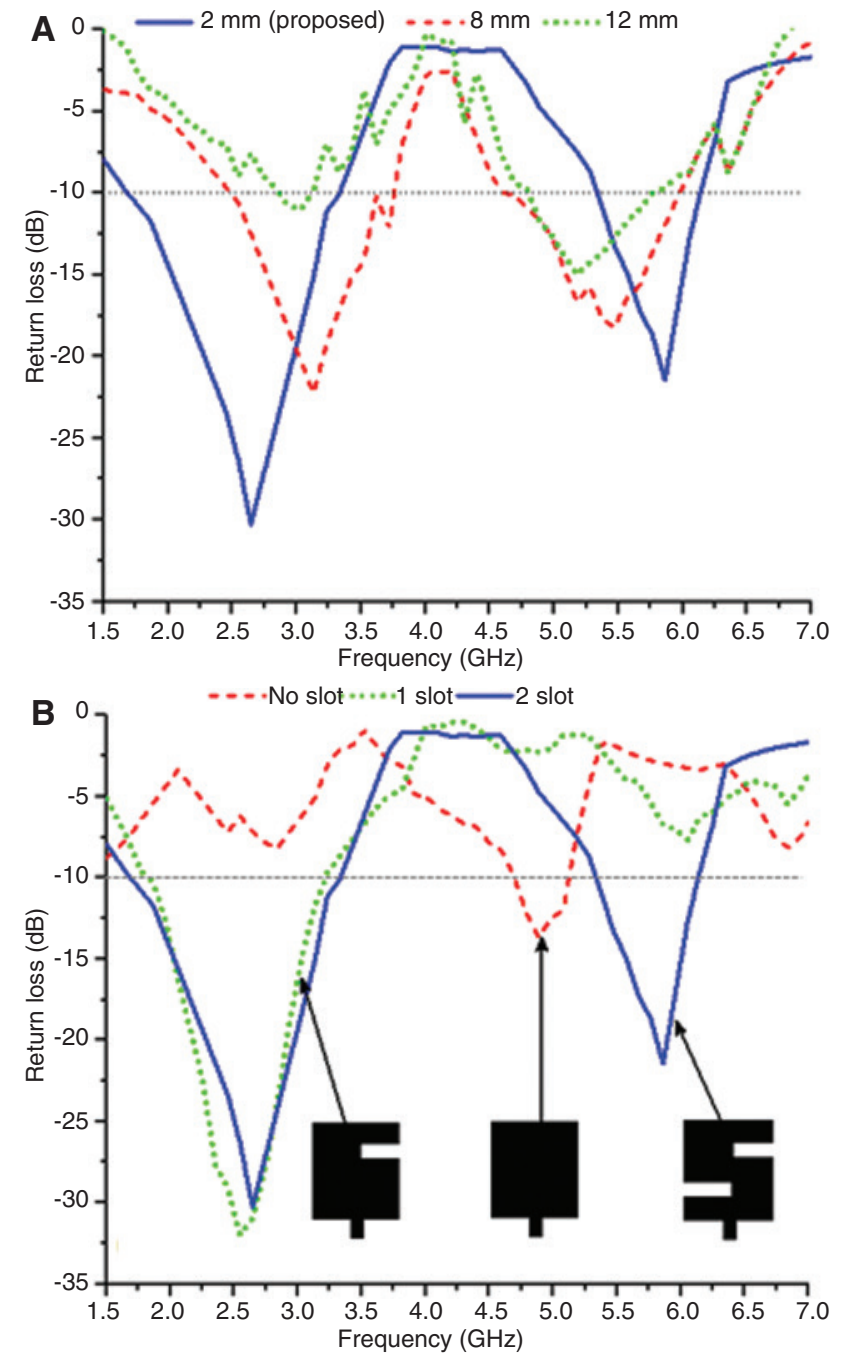

Figure 3 Effects of (A) ground plane length and (B) slots on the return loss of the antenna.

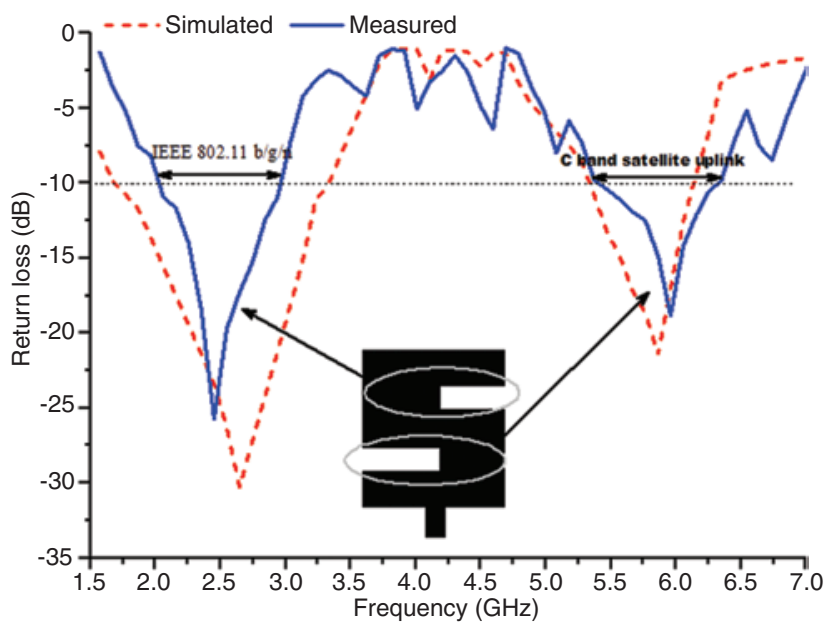

Figure 4 Simulated and measured reflection coefficients (S11) dB of the proposed antenna prototype. 
formulation as presented in [23]. The length of the radiating patch is responsible for generating the lower resonant frequency. Meanwhile, the upper resonant frequency is dominated by the slot location and dimension. The dimension of the slots, i.e., W_2, W_3, L_2, and L_3, have been carefully adjusted to determine the upper resonance. The dimensions of the ground plane also have a major effect on the return loss value and resonance.

The effect of the different substrate materials on the return loss of the proposed antenna is shown in Figure 2. It can be clearly observed that the proposed antenna offers a wider bandwidth and an adequate return loss value compared with two other reported materials. Although the antenna with modified epoxy material substrate provides almost similar bandwidth, the resonances are shifted to the lower frequency compared with the proposed polymer resin. Moreover, the fiberglass ceramic-PTFE substrate is quite expensive compared with the proposed substrate material. The dielectric properties of the substrate materials are tabulated in Table 2.

Figure 3 represents the effect on the return loss of the proposed antenna caused by ground plane lengths and slots on the radiating patch. Ground plane dimension is one of the important parameters that dominate resonant frequency and bandwidth. According to the patch antenna radiation principle, an equal current but with opposite direction is created on the ground plane and accumulates with in-phase on the patch antenna. The length of the ground plane has a dominant effect on resonant frequency and impedance bandwidth [24, 25]. It can be easily seen that the return loss value of the proposed antenna is lowest and that the bandwidth is better with a 2-mm-long ground plane. The proposed antenna was fabricated and measured with

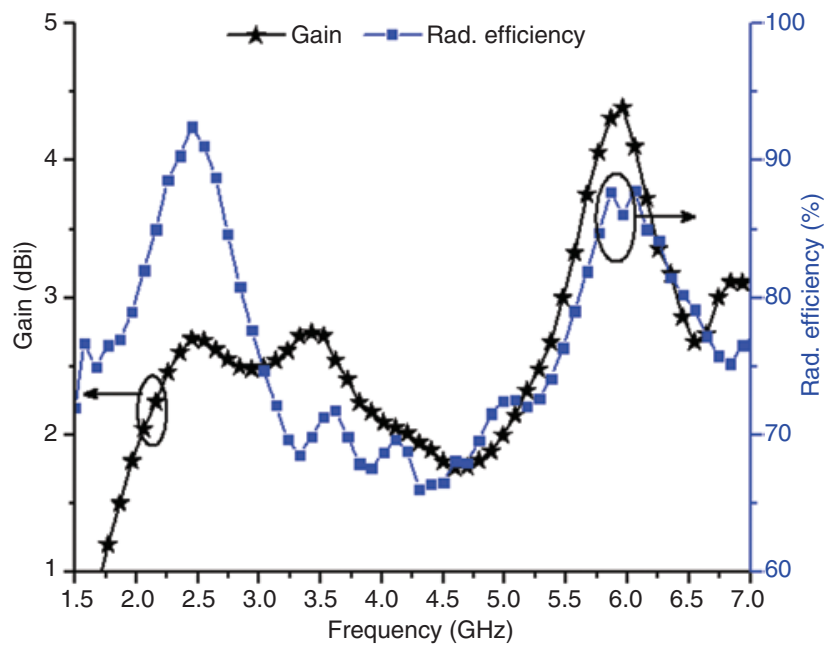

Figure 5 Measured gain and normalized radiation efficiency of the proposed antenna. optimized 2-mm-long ground plane. It also can be clearly observed from Figure 3B that with single slot the antenna can achieve only lower band, whereas the desired two bands can be achieved using two slots over the radiating patch.

\section{Performance analysis}

With the optimized dimension, a dual resonant patch antenna has been fabricated and a series of measurements are carried out in a standard far-field anechoic chamber. The standard rectangular shaped anechoic chamber is about $5.5 \times 4.5 \mathrm{~m}^{2}$ with height of $3 \mathrm{~m}$, and its interior surfaces are covered with pyramidal radiation absorbent materials. The antenna prototype is placed in such a way that the z-axis faces the double-ridged reference horn antenna. An Agilent's E8362C series vector network analyzer with a range of up to $20 \mathrm{GHz}$ has been used for measuring antenna performance in terms of return loss, gain, and radiation patterns.

Figure 4 represents the comparison of the simulated and measured results of the proposed antenna in terms of return losses against the frequency. Slight dissimilarities can be observed between simulated and measured return loss. A possible reason for this difference could be the soldering effect or the loss of the connecting cable between the antennas and the controller. Although the measurement setup was calibrated using the Agilent automatic calibration kit. Referring to the Figure 4, it can be seen that the upper slot of the radiating patch is responsible for generating the lower frequency band and the slot in the lower part dominates the upper band. The bandwidth and both upper and lower resonance are optimized by adjusting the ground plane size along with the patch length and slots. It has been observed from the result that the $-10-\mathrm{dB}$ return loss

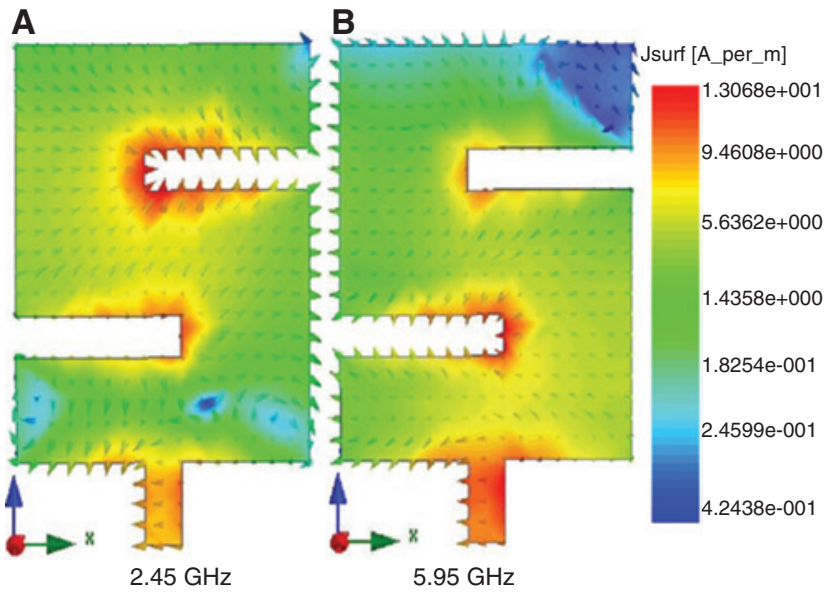

Figure 6 Surface current distribution of the proposed antenna at (A) $2.45 \mathrm{GHz}$ and (B) $5.95 \mathrm{GHz}$. 
bandwidths of the proposed antenna are $0.95 \mathrm{GHz}(38.78 \%)$ from 2.03 to $2.98 \mathrm{GHz}$ and $0.97 \mathrm{GHz}$ (16.3\%) from 5.38 to $6.35 \mathrm{GHz}$ covers the IEEE $802.11 \mathrm{~b} / \mathrm{g} / \mathrm{n}$ applications and C-band telecommunication satellite uplinks. The measured gain and efficiency of the proposed antenna are shown in Figure 5. The measured average gain of 2.52 and $3.94 \mathrm{dBi}$ have obtained at the lower and upper bands, respectively. Three antenna measurement system, i.e., two identical horn antennas and antenna under test have used for gain measurement [26]. Meanwhile, the radiation efficiency seems to reach $91.3 \%$ and $87.7 \%$ on average for the upper and lower bands centered at 2.45 and $5.95 \mathrm{GHz}$, respectively.

Figure 6 illustrates the surface current distribution on the radiating element of the proposed microstrip patch antenna. It can be seen that at the lower band, the current distribution is much stronger in the nearby upper slot, whereas at the upper band, it is apparently visible that the flowing surface currents become much stronger in the adjacent area near lower slot and microstrip feed line. This current distribution phenomenon also validates the effect of the slots in generating the resonant frequencies.

The radiation performance was measured in a standard anechoic chamber. The $\mathrm{E}$ and $\mathrm{H}$ plane normalized radiation pattern of the proposed antenna at $2.45 \mathrm{GHz}$ is presented in Figure 7A, and Figure 7B shows the $\mathrm{E}$ and $\mathrm{H}$ plane radiation pattern at $5.95 \mathrm{GHz}$. The co-cross-polarization of the proposed antenna in the $\mathrm{E}$ and $\mathrm{H}$ plane radiation pattern is shown in the figure. From the radiation patterns,
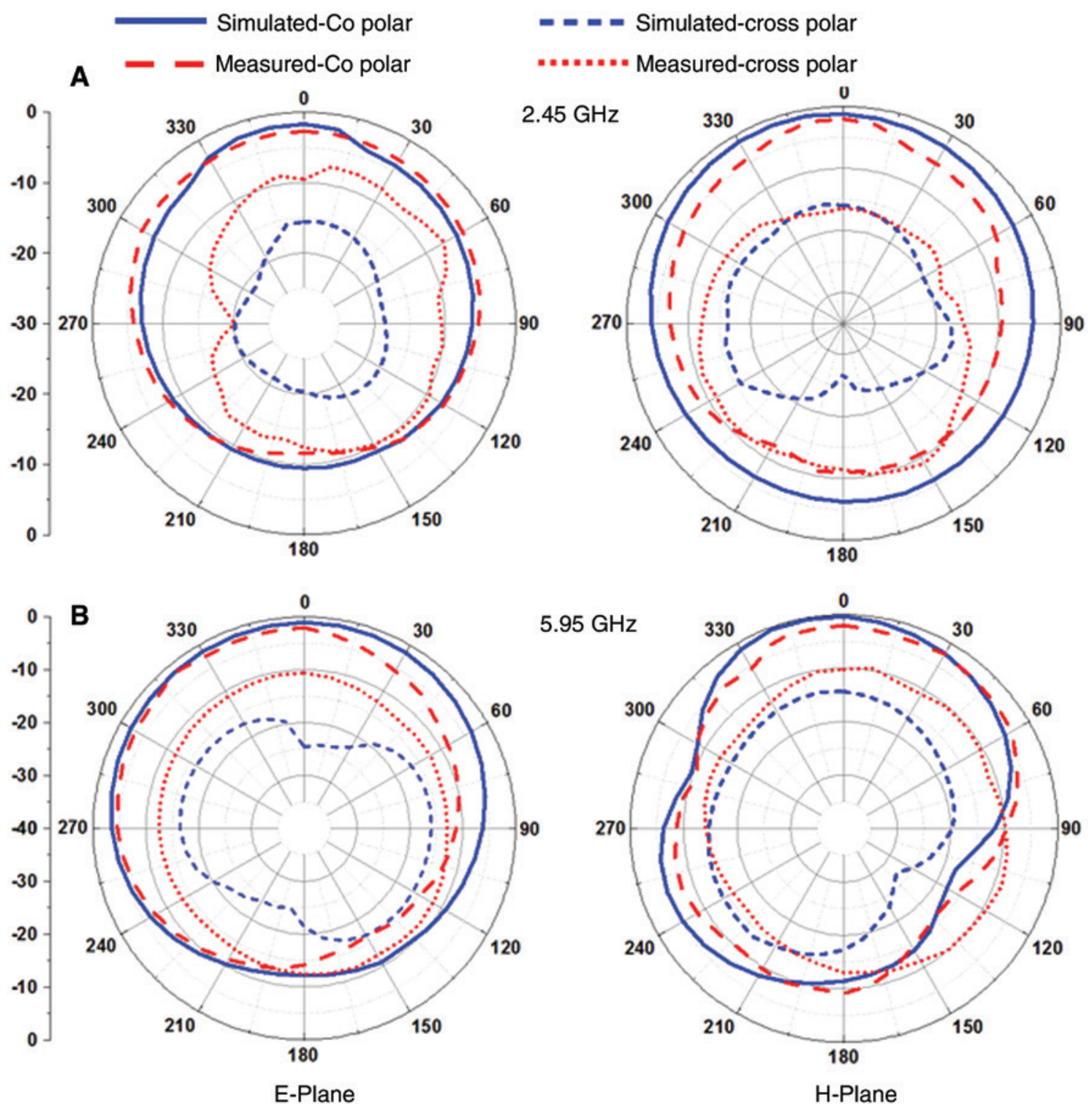

Figure 7 Measured $\mathrm{E}$ and $\mathrm{H}$ plane radiation patterns of the proposed antenna at both resonant frequencies (A) $2.45 \mathrm{GHz}$ and (B) $5.95 \mathrm{GHz}$. 
Table 3 Comparison between the proposed antenna and some existing antennas.

\begin{tabular}{|c|c|c|c|c|c|}
\hline References & Substrate material & $\varepsilon_{\mathrm{r}}$ & Size $\left(\mathrm{mm}^{2}\right)$ & Bandwidth (MHz) & Gain (dBi) \\
\hline Proposed & Glass-reinforced polymer resin composite & 4.6 & $8 \times 10$ & 1000,900 & $2.52,3.94$ \\
\hline [3] & Arlon $25 \mathrm{~N}$, reinforced fiberglass & 3.28 & $100 \times 100$ & 45,20 & $1.45,1.1$ \\
\hline [19] & FR4, reinforced fiberglass & 4.6 & $30 \times 30$ & 2370,2180 & $2.5,3.07$ \\
\hline$[27]$ & FR4, reinforced fiberglass & 4.6 & $108 \times 108$ & 220,600 & $2.7,5.04$ \\
\hline
\end{tabular}

it can be evidently seen that the cross-polarization for both the frequencies are larger than expected, which is may be due to the $\mathrm{x}$-directed current. The approximately symmetric and steady radiation patterns of the proposed antenna reasonably make it suitable to furnish the services associated with the intended frequency bands. The performance criteria of the proposed antenna are compared with some of the reported similar work and have been tabulated in Table 3. By analyzing the tabulated data, it can be concluded that the proposed antenna has smaller dimension while it outperforms in terms of bandwidth and gain by comparing with the rest of the reported antennas.

\section{Conclusion}

A compact S-shaped microstrip line-fed slotted patch antenna prototype with a dimension of $8 \times 10 \mathrm{~mm}$ has been designed and printed on the PCB. The measured impedance bandwidth (return loss of less than $-10 \mathrm{~dB}$ ) of 0.95 and $0.97 \mathrm{GHz}$ ranges from 2.03 to $2.98 \mathrm{GHz}$ and from 5.38 to $6.35 \mathrm{GHz}$, respectively, have achieved from the proposed antenna. Average gains of 2.52 and $3.94 \mathrm{dBi}$ have measured from the proposed antenna at the lower and the upper bands correspondingly. The effects of three different substrate materials, ground plane lengths $(2,8$, and $10 \mathrm{~mm})$, and slots on return loss have analyzed. The measured $\mathrm{E}$ and $\mathrm{H}$ plane radiation pattern and simulated current distribution are analyzed for the both resonant frequencies 2.45 and $5.95 \mathrm{GHz}$. The performance result shows that the proposed antenna is suitable for IEEE $802.11 \mathrm{~b} / \mathrm{g} / \mathrm{n}$ applications and C-band telecommunication satellite uplinks.

\section{References}

[1] Pozar DM, Schaubert DH. Microstrip Antennas: The Analysis and Design of Microstrip Antennas and Arrays. John Wiley \& Sons: Hoboken, NJ, 1995.

[2] Carver KR, Mink J. IEEE Trans. Antennas Propag. 1981, 29, 2-24.
[3] De Cos M. E. and F. Las-Heras. Int. J. Antennas Propag. 2012, 2012, 1-7.

[4] Ahsan MR, Ullah MH, Islam MT. J. Comput. Electron. 2014, 13, 989-995.

[5] Islam MT, Ullah MH, Singh M), Faruque MRI. Materials 2013, 6, 3226-3240.

[6] Jung Y-K, Lee B. IEEE Trans. Antennas Propag. 2012, 60, 786-791.

[7] Ullah MH, Islam MT, Jit MS, Misran N. J. Intell. Mater. Syst. Struct. 2012, 23, 1827-1832.

[8] Kamogawa K, Tokumitsu T, Aikawa M. IEEE Trans. Microwave Theory Tech. 1996, 44, 2431-2437.

[9] Tang X, Wong H, Long Y, Xue Q, Lau KL. IEEE Trans. Antennas Propag. 2012, 60, 1588-1592.

[10] Wong K-L, Chang C-H, Chen B, Yang S. Microwave Opt. Technol. Lett. 2006, 48, 474-476.

[11] Floc'h J-M, Rmili H. Microwave Opt. Technol. Lett. 2006, 48, 1639-1645.

[12] Chang C-H, Wei W-C, Ma P-J, Huang S-Y. Microwave Opt. Technol. Lett. 2013, 55, 2835-2841.

[13] Gianvittorio JP, Rahmat-Samii Y. IEEE Antennas Propag. Mag. 2002, 44, 20-36.

[14] Ullah MH, Islam MT, Mandeep JS, Misran N. Appl. Phys. Mater. Sci. Process. 2013, 110, 199-205.

[15] Vera-Dimas JG, Tecpoyotl-Torres M, García-Limón JA, Zezzatti CA. Procedia Eng. 2012, 35, 155-164.

[16] An WX, Wong H, Lau KL, Li SF, Xue Q. IEEE Trans. Antennas Propag. 2012, 60, 1592-1595.

[17] Wong K-L, Chang C-H. IEEE Trans. Antennas Propag. 2006, 54, 1100-1104.

[18] Wang H, Zheng M. IEEE Antennas Wireless Propag. Lett. 2011, 10, 569-572.

[19] Yang K, Wang H, Lei Z, Xie Y, Lai H. Electron. Lett. 2011, 47, 685-686.

[20] Liu W-C, Chen W-R, Wu C-M. IEE Proc. Microwave Antennas Propag. 2004, 151, 473-476.

[21] Low ZN, Cheong JH, Law CL. IEEE Antennas Wireless Propag. Lett. 2005, 4, 237-239.

[22] ANSYS $^{\circledR}$ High Frequency Structural Simulator (HFSS). ANSYS: Canonsburg, PA.

[23] Balanis CA. John Wiley \& Sons: Hoboken, NJ, 2005.

[24] Koohestani M, Moghadasi MN, Virdee BS. IET Microwave Antennas Propag. 2011, 5, 1683-1689.

[25] Ahsan MR, Islam MT, Ullah MH, Misran N. Sci. World J. 2014, 2014, 856504.

[26] Evans GE. Artech House: Norwood, MA, 1990.

[27] Tiang J-J, Islam MT, Misran N, Mandeep JS. Prog. Electromagn. Res. 2011, 120, 499-512. 